\title{
PARAMETRIC STUDY ON CO-FEEDING OF MUNICIPAL SOLID WASTE AND COAL IN AN IGCC POWER PLANT WITH PRE- COMBUSTION CARBON CAPTURE
}

\author{
Md. Shahriar Hossain, Suprio Kamal, Mahbub Chowdhury, Md. Tariful Islam \\ and Kawnish Kirtania* \\ Department of Chemical Engineering, Bangladesh University of Engineering and Technology \\ Dhaka - 1000, Bangladesh
}

\begin{abstract}
Municipal solid waste (MSW) is one of the top contributors in greenhouse gas (i.e. methane) emissions particularly from landfill disposals. However, it could be a remarkable source of renewable energy. In Bangladesh, generation of municipal solid waste is at least 2.7 million tonne per year in the major cities, implying a heavy environmental burden. On the other hand, there are several coal-based power plants are in the pipeline to meet the increasing energy demand in Bangladesh with the potential of significant $\mathrm{CO}_{2}$ emission. To find a remedy to the above situation, a power plant using Integrated Gasification and Combustion Cycle (IGCC) technology with pre-combustion carbon capture is considered in this study. IGCC has the advantage of producing high quality syngas from a wide variety of feed and assists in the capture of $\mathrm{CO}_{2}$ at a lower cost while providing high electric efficiency. The power plant was simulated by commercial simulation packages (Aspen PLUS ${ }^{\mathrm{TM}}$ and Aspen HYSYS ${ }^{\text {TM}}$ ) using MSW and bituminous coal (Indonesian) as a combined feed. With a feed rate of 1800 tonne per day, Syngas produced from an entrained flow type gasifier was then treated for $\mathrm{CO}_{2}$ removal using mono-ethanol amine (MEA) solvent after necessary shift in a high temperature shift reactor. About $91 \%$ efficiency was achieved in the shift reactor while the $\mathrm{CO}_{2}$ capture efficiency was varied for this study from $30 \%$ to $85 \%$. Further parametric variation was studied by varying the moisture content of MSW and MSW to coal feed ratio. Through combustion of the $\mathrm{H} 2$ rich syngas in a gas turbine and subsequent steam cycle with reheat resulted in $125 \mathrm{MW}$ of electricity at an efficiency of $28.95 \%$ while capturing $50 \%$ of the $\mathrm{CO}_{2}$ generated in the process for an MSW to Coal feed ratio of 1:1. With variation in moisture content especially during monsoon season, the plant efficiency could be affected remarkably. On the other hand, it was observed that the energy requirement varied from 6 to $8 \mathrm{MW}$ for every $10 \%$ increase in $\mathrm{CO}_{2}$ capture quantity. Overall, by capturing $50 \%$ of the generated $\mathrm{CO}_{2}$, it is possible to reduce the emission of a same size ultra-supercritical coal-based power plant from about $700 \mathrm{~kg} \mathrm{CO} / \mathrm{MWh}$ to about $360 \mathrm{~kg}$ of net $\mathrm{CO}_{2} / \mathrm{MWh}$ incorporating co-feeding and pre-combustion capture in an IGCC power plant.
\end{abstract}

Keywords: MSW, Gasification, Waste to Energy, IGCC, $\mathrm{CO}_{2}$ Capture, Clean Energy.

\section{Introduction}

Climate change, energy security, environmental pollution, MSW management are distinct but intricately coupled challenges that have holistic impacts on the national economy, local and global ecology, and hence the lifestyle of human civilizations. Power generation from fossil fuelspredominantly coal, is the most significant contributor for the exacerbation regarding these issues and so a technological paradigm shift is required.

The developing countries of South East Asia are witnessing an increasing demand for electric power [1]. Coal being cheapest of all fossil fuels and having ease of transport, storage, and well-established infrastructure for thermal power generation is the first choice for meeting the transient demand of an - emerging industrial economy. However, the thermoelectric power schemes produce significant emissions and have a large water consumption footprint which lead to environmental pollution, climate change and recurrence of natural calamities. This pertains rearrangements of logistics and resources of a nation in agriculture, healthcare and education; hindering stable economic growth. So, the use of fossil fuels for rapid development poses a paradox with the traditional technology being used [2]. As of 2017, coal alone accounts for 14,502 million tonnes $\mathrm{CO}_{2}$ emission which is about $40 \%$ of the $\mathrm{CO}_{2}$ emissions from fossil fuel use (IEA, 2017). Countries like India, China, Vietnam, Thailand, Bangladesh, Cambodia, Philippines, Laos, Malaysia will continue to increase their coal consumption to meet energy demands [1]. It is unlikely that this consumption will shut down within a time frame consistent with climate targets (IEA, 2016). 


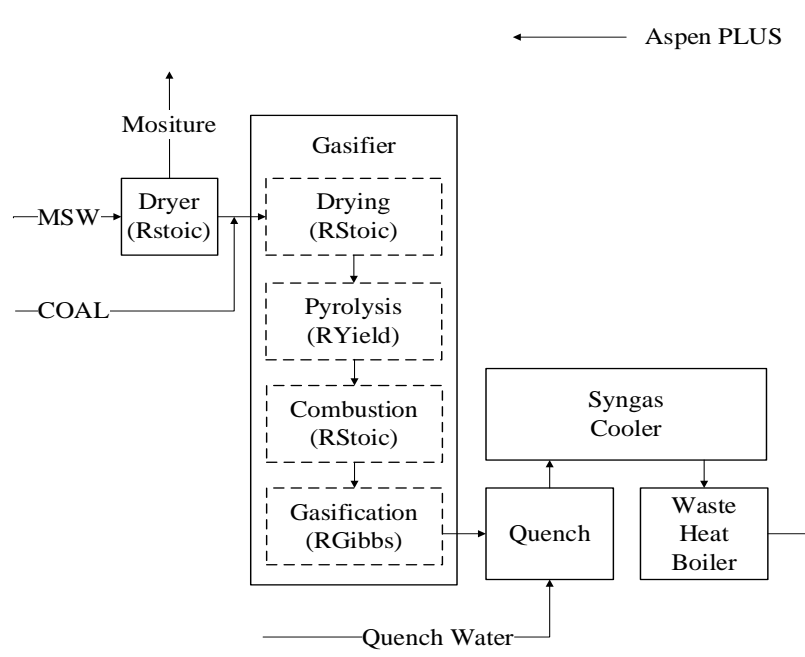

Fig 1 Block diagram of the IGCC process model

IGCC provides a solution to all these issues. Here, fuel is gasified to produce Syngas that is burned to generate electricity through a gas turbine. The remaining energy in the flue is extracted to make steam that can provide additional electricity via a steam turbine. The gasification reactions can handle a wide variety of feedstocks, lowers the production of $\mathrm{SO}_{\mathrm{x}}$ and $\mathrm{NO}_{\mathrm{x}}$ [3], and has a lower water footprint due to the combined cycle. Pre-combustion $\mathrm{CO}_{2}$ percentage is high in IGCC, leading to a more energy-efficient carbon capture and storage (CCS) scheme downstream. Captured $\mathrm{CO}_{2}$ can be sequestered underground in geological caverns, used in enhanced oil recovery schemes, or can be subjected to ex-situ or in-situ mineral carbonization to achieve a neutral or a negative carbon powerplant depending on feedstock composition $[4,5,6]$. For this reason, co-feeding coal with MSW or biomass is preferable [6]. MSW contains food wastes, organic debris like papers, plastics, rubbers, lignocellulosic materials and typically has an LHV of $7 \mathrm{MJ} / \mathrm{kg}$ [7]. With increasing urbanization, the amount of MSW generated is becoming more significant. In the US, 238.5 million tonnes of MSW were produced, of which $52.5 \%$ were landfilled, and $12.5 \%$ were incinerated with only $12.8 \%$ energy recovered $[8,7]$. Japan leads the world in energy extraction from MSW by having 78\% WTE conversion [7]. Southeast Asian countries have minimal WTE facilities [8,9]. So, there are scope in the development of WTE facilities, mainly by IGCC.

Pilot-scale IGCC includes ELCOGAS IGCC with pre-combustion CCS with a $335 \mathrm{MW}$ capacity, the EAGLE project, the Osaki CoolGen Project with a 166 MW capacity [5]. Major existing and planned IGCC commercial plants include Kemper County, Buggenum, Wabash River, Tampa, Pernis, Priolo Gargallo, Puertollano, Sarlux, Nehishi, Versova, Knox Country, Nakoso with capacities varying from 115-618 MW and CCS technology in some [10]. The LHV efficiency of commercial IGCC plants ranges

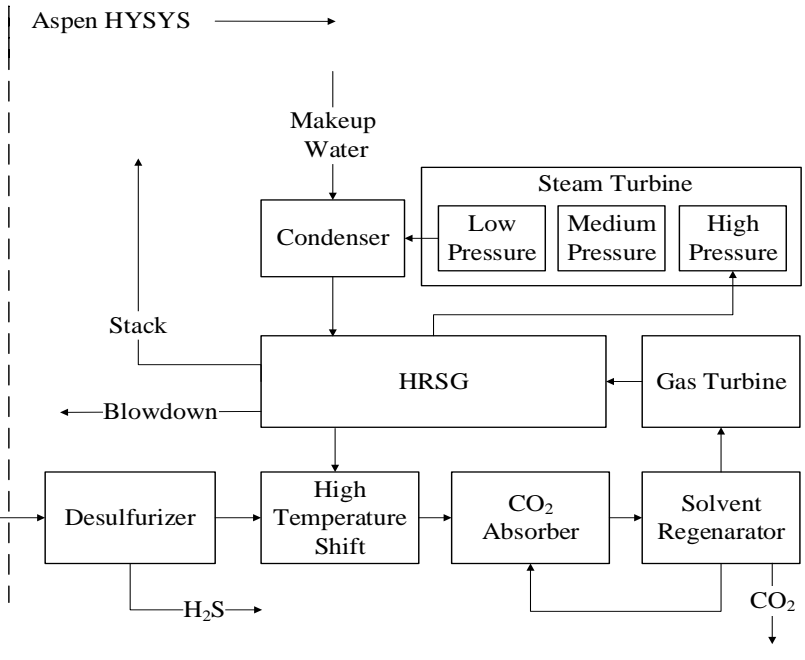

between $36 \%-42.2 \%$ depending on the feedstock, type of CCS technology used (if any), and extent of process integration [10]. The major developments of new IGCC projects include Don Valley Plant, Tenaska plant, Dongguan Taiyangzhou plant, Jiangsu plant with capacities ranging from 300-1200 MW with low-lost fuel co-firing, and CCS. [10]

While several pilot-scale plants are in operation or being planned to be set up, it is becoming essential to realize the true potential of the large-scale IGCC plants handling mixed feedstock with CCS. In this work, we carried out a parametric study on a fullscale IGCC plant using MSW and coal as feedstock to understand the operational flexibility and synergy among the different processes (Gasification, WaterGas Shifting, $\mathrm{CO}_{2}$ Absorption, Combined Cycle). We further evaluated how the processes behave holistically given changes in boundary conditions like feedstock compositions, feedstock preprocessing, thermodynamics of WGS reaction and $\mathrm{CO}_{2}$ absorption percentage.

\section{Model Description}

A steady-state model of the IGCC process was developed in two parts with the help of Aspen Suite of process simulators. The solid handling and Gasification process simulation were performed in Aspen PLUSTM and the Syngas cleaning, Shift conversion, Carbon Capture, and power generation in Aspen HYSYS ${ }^{\mathrm{TM}}$. Stream data was transferred from Aspen PLUS ${ }^{\mathrm{TM}}$ to Aspen HYSYS ${ }^{\mathrm{TM}}$ by exporting stream data. The model takes in MSW and Coal data as input and analyzes the effect of the different chosen parameters on the process. The following assumptions were made while developing the model.

- The process is steady-state, isothermal, and all the unit processes and operations are uniform in pressure. 
- Gasification occurs in four primary steps Drying, Pyrolysis, Combustion, and Gasification.

- All gasification products except $\mathrm{CO}, \mathrm{CO}_{2}, \mathrm{H}_{2}$, $\mathrm{CH}_{4}, \mathrm{H}_{2} \mathrm{~S}$, and $\mathrm{H}_{2} \mathrm{O}$ are ignored.

- $\mathrm{N}_{2}$ is considered to be inert throughout the process.

- $\quad$ The MSW considered in the process is assumed to be comprised of only biogenic waste.

- Coal and MSW are assumed to be made up of only Carbon, Hydrogen, Oxygen, Nitrogen, Sulphur, and Ash.

- Heat loss from the gasifier is considered $2 \%$ of the total heat recovered from gasifier. Other mechanical losses are ignored.

- No entrained particle remains after direct quenching of Syngas.

The simulation process is represented in a block diagram in Fig. 1. MSW is first dried and then mixed with coal to enter the gasifier. The extent of drying is controlled by Stoichiometric reactor coupled with Fortran subroutines inside Aspen PLUS ${ }^{\text {TM }}$.

The proximate and the ultimate analysis of the two fuels are given in Table 1. Typically, MSW in megacities like Dhaka, Bangladesh, contains an average $12 \%$ of plastics [11], which contribute to the non-renewable carbon content of the MSW fuel, while coal contributes to the remaining $88 \%$.

Table 1

Characteristics of two feedstock - Coal (Indonesia) and MSW on dry basis $[12,13]$

\begin{tabular}{llcc}
\hline $\begin{array}{l}\text { Proximate } \\
\text { Analysis }^{\text {a }}\end{array}$ & Ash & $\begin{array}{c}\text { Coal } \\
(\% w / w)\end{array}$ & $\begin{array}{c}M S W \\
(\% w / w)\end{array}$ \\
\hline & Volatile Carbon & 48.46 & 75.83 \\
& Fixed Carbon & 45.14 & 11.69 \\
\hline Ultimate $_{\text {Analysis }}{ }^{\text {b }}$ & & Coal & $M S W$ \\
\hline & $\mathrm{C}$ & $(\% w / w)$ & $(\% w / w)$ \\
\hline & $\mathrm{H}$ & 74.61 & 47.61 \\
& $\mathrm{O}$ & 5.13 & 6.07 \\
& $\mathrm{~N}$ & 10.69 & 43.85 \\
& $\mathrm{~S}$ & 8.72 & 2.19 \\
\hline Heating Values & & 0.85 & 0.28 \\
\hline & $\mathrm{HHV}(\mathrm{kJ} / \mathrm{kg})$ & 25500 & 17886 \\
& $\mathrm{LHV}(\mathrm{kJ} / \mathrm{kg})$ & 24858 & 16827 \\
\hline
\end{tabular}

${ }^{a}$ dry basis, ${ }^{b}$ dry ashless basis

\subsection{Drying}

Before mixing with coal, the MSW goes through an initial drying process in a steam kiln, simulated with an RStoic reactor block in aspen plus. Then, as the combined feedstock enters the gasifier, the excess moisture is driven off first, simulated by an Aspen PLUS $^{\mathrm{TM}}$ stoichiometric reactor, RStoic. FORTRAN subroutines inside the reactor control the extent of drying. It is assumed that the feedstock dries completely before the pyrolysis stage of gasification.

\subsection{Pyrolysis}

This stage was simulated by an Aspen PLUS ${ }^{\mathrm{TM}}$ RYield reactor. In this step, the feedstock devolatizes into Carbon, Hydrogen, Nitrogen, Oxygen, and Sulfur, and Ash. The yield distribution is specified by FORTRAN subroutines according to the combined feedstock's ultimate analysis which was calculated by the software. The stream containing these components is then fed to the combustion step.

\subsection{Combustion}

An Aspen PLUSTM Rstoic reactor was used to simulate this step. The rate of conversion of total carbon was assumed to be $80 \%$ in the reactor. The selectivity of $\mathrm{CO}$ and $\mathrm{CO}_{2}$ formation was given by the ratio between their heats of reaction. Pure $\mathrm{O}_{2}$ gas below the stoichiometric ratio and pressurized $\mathrm{CO}_{2}$ were introduced into the process. The unreacted carbon and the produced gases, and the other component are then fed to the gasification step. It is the combustion step that acts as the primary source of heat for the whole gasification process.

\subsection{Gasification}

This step was simulated in an Aspen PLUS ${ }^{\text {TM }}$ RGibbs reactor, governed by the Gibbs free energybased model to determine the final composition of the gasification product gases. The temperature was maintained at $1400{ }^{\circ} \mathrm{C}$ by producing Medium pressure steam from the process. The produced Syngas moves on to the Quench system leaving the ash behind as molten slag.

\subsection{Quench and Heat recovery}

The hot gases from the gasification process were quenched with water to reduce the temperature and increased the moisture content which later assisted in the shift reaction system. The Syngas then passed through the syngas cooler and waste heat boiler, simulated by a pair of heat exchangers - producing high and medium pressure steams, respectively. The heat recovered from here contributed to the Heat Recovery Steam Generator.

\subsection{Syngas Cleaning}

The cooled syngas was passed through the desulphurizer, where $\mathrm{H}_{2} \mathrm{~S}$ gas was removed from the syngas. Complete removal of $\mathrm{H}_{2} \mathrm{~S}$ in a $\mathrm{ZnO}$-based catalytic reactor was considered here. 


\subsection{High Temperature Shift Reactor}

In High Temperature Shift Reactor, the $\mathrm{CO}$ present in clean Syngas was converted to $\mathrm{CO}_{2}$ with the help of steam, and more $\mathrm{H}_{2}$ was produced in the process. This process was simulated by an Aspen HYSYS ${ }^{\text {TM }}$ Equilibrium Reactor, which calculates the final composition of the shifted syngas in the specified temperature. Parameters like the CO: Steam ratio, and the temperature were modified to observe their impact. The $\mathrm{CO}_{2}$-rich syngas then sent to the $\mathrm{CO}_{2}$ absorber section.

\section{8. $\mathrm{CO}_{2}$ Absorber and Stripper}

$30 \%$ MEA solution was used as the lean solvent for absorption. The rich MEA stream exited the absorber at the bottom of the column and enters the stripper, where the reaction is reversed. The liberated $\mathrm{CO}_{2}$ left the stripper column, and the remaining MEA was recycled back to the absorber. A solution of MEA was introduced as a makeup for the purge stream. The process was simulated by an Absorber Column operating at system pressure and a Distillation column operating at lower pressure, respectively, in Aspen HYSYS ${ }^{\text {TM }}$. Parameters like Mass to $\mathrm{CO}_{2}$ were controlled to see its effect on the capture performance of the system. The $\mathrm{H}_{2}$ rich syngas was then fed to the gas turbine.

\subsection{Power Generation}

An Equilibrium reaction model was used to simulate the combustion chamber with compressed air and an Expander to simulate the turbines. The exhausted hot stack gases pass through a network of heat exchangers simulating the Heat Recovery Steam Generator, which generates the steam required for the steam cycle and unit processes. The steam turbine uses steam at three different pressures, simulated by three expanders.

\section{Experimental Methodology}

The developed model for the process is used to analyze the effect of the chosen parameters. Gasifier inlet moisture and the co-feeding ratio were varied to see its effect on Cold Gas Efficiency. In the High temperature shift reactor, the Steam: CO ratio was varied to see the effect on the extent of conversion, $\mathrm{CO}$, and $\mathrm{CO}_{2}$ content in the dry syngas. The MEA: $\mathrm{CO}_{2}$ mass ratio was varied to observe its effect on the percentage of $\mathrm{CO}_{2}$ in the absorber inlet captured and the regenerator reboiler duty.

\section{Results and Discussion}

\subsection{Cold Gas Efficiency}

Cold Gas efficiency is the ratio of the lower heating value of the resulting Syngas from a gasification process to the lower heating value of the gasified fuel. In this model, the formed syngas' primary gasification products are $\mathrm{H}_{2}$ and $\mathrm{CO}$. The amount of these two species thus controls the Lower heating value of the syngas. Figure 2 a shows that the CGE went up as more coal was used in the feed. This is primarily due to the availability of more carbon in the feed due to more coal. On the other hand, if more MSW is used, the overall moisture content in the gasifier inlet increases, impacting the cold gas efficiency of the gasifier as the water content in the

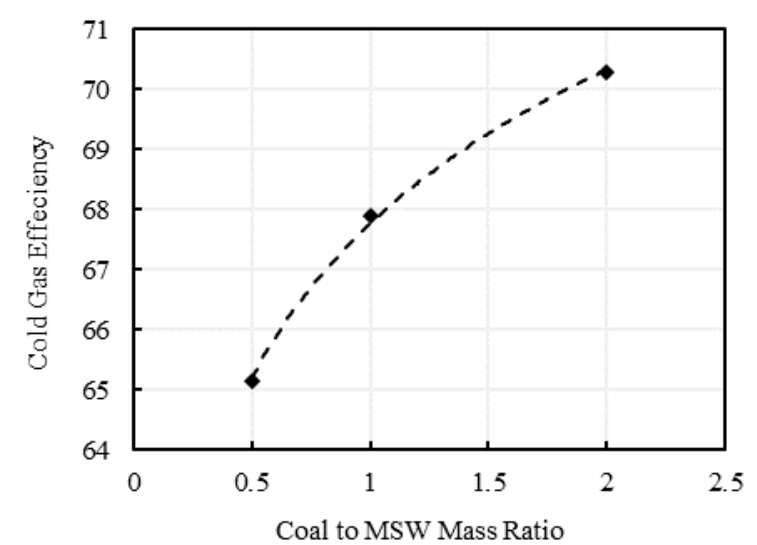

(a)

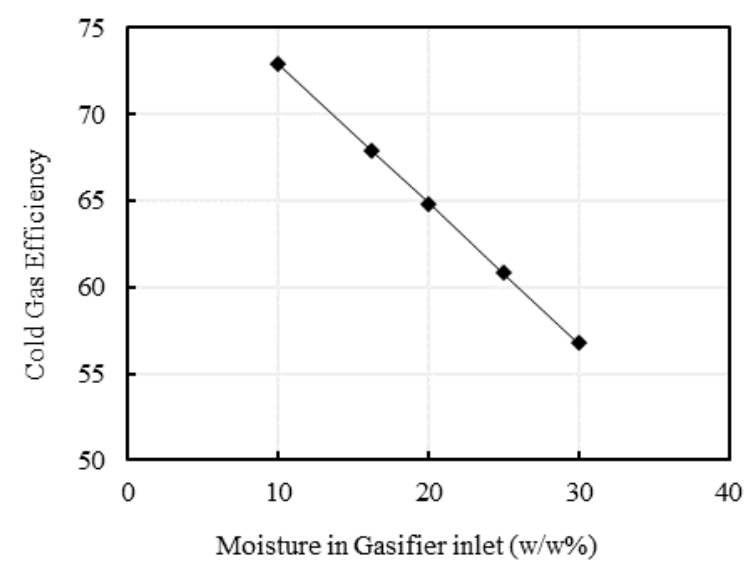

(b)

Fig 2 Effect on Cold Gas Efficiency for (a) different Coal to MSW Ratios, (b) Different Gasifier feed moistures

resulting syngas rises. The moisture content of the combined feed of the gasifier containing dried MSW and coal was varied from $10 \%$ to $30 \%$ to study the change in CGE, and the effect can be seen in fig $2 b$. 


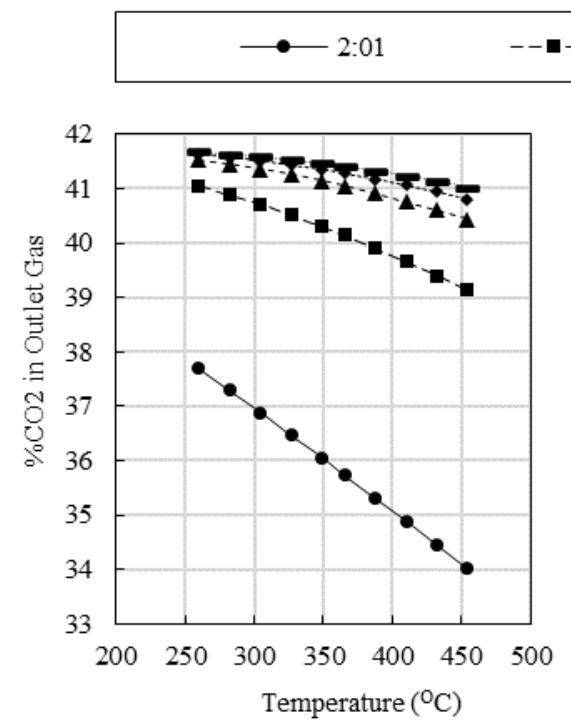

(a)

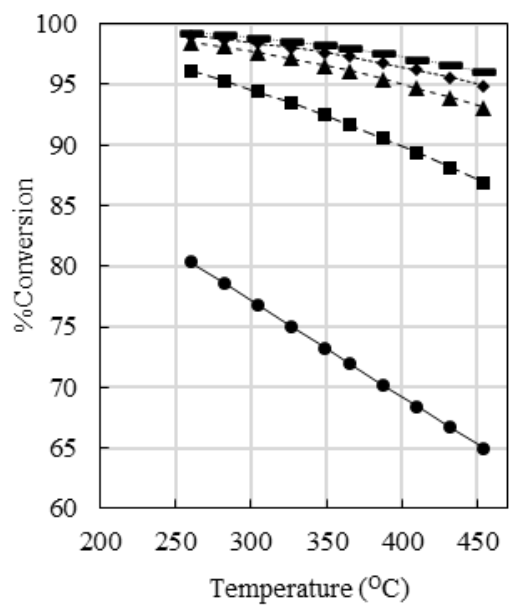

(b)

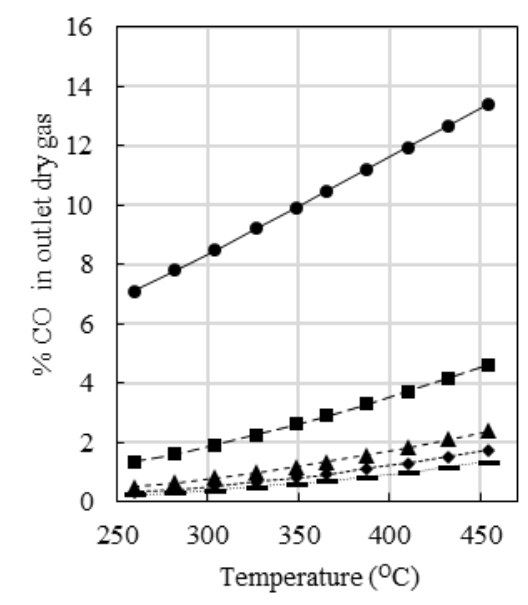

(c)

Fig 3 Effect of various Steam: $\mathrm{CO}$ ratio on (a) $\% \mathrm{CO}_{2}$ in outlet dry gas at various temperature, (b) \%Conversion in shift reactor at various temperature, (c) \% $\mathrm{CO}$ in outlet dry gas at various temperature

Higher CGE suggests higher quality Syngas and generally better power generation. The results showed that a higher Coal: MSW ratio led to higher CGE, but a higher Coal: MSW ratio would also mean that the nature of the particles in gasifier feed had changed and was abundant in coal particles which needed more time to convert. Thus, a higher residence time would be required in the gasifier resulting in a larger gasifier. We also see the tendency of the CGE to level off at higher Coal: MSW ratios, so an optimum value is required to be selected to obtain optimum efficiency.

Higher moisture in the feed also reduces CGE, so moisture should be kept as low as possible in the gasifier inlet. The primary source of moisture in the process is the MSW, so it needs to be dried by a considerable extent before gasification.

\subsection{Steam:CO Ratio}

The ratio of added steam in HTS to the amount of $\mathrm{CO}$ present in the Syngas was modified. Five sets of ratios were tested to see the effects on the $\mathrm{CO}_{2}$ content in the resultant syngas, the extent of conversion of $\mathrm{CO}$ and $\mathrm{CO}$ content in Syngas, presented in Fig 3a, b, c, respectively.

The extent of conversion increase as the Steam to $\mathrm{CO}$ ratio is increased, and thus the amount of $\mathrm{CO}_{2}$ increases and is evident from Fig $3 \mathrm{a}$ and $3 \mathrm{~b}$. A similar effect could be observed in Fig $3 \mathrm{c}$ as the amount of $\mathrm{CO}$ went down with increased steam: $\mathrm{CO}$ ratio. In all five cases of the steam: $\mathrm{CO}$ ratio, we can see that the desired effect was promoted at lower temperatures and continued to drop off as the temperature rises. A drastic increase in conversion was observed as the steam:CO ratio was changed from $2: 1$ to $5: 1$, but a similar increase in conversion was not apparent for the subsequent increments in the steam:CO ratio.

The results indicate that higher steam: $\mathrm{CO}$ ratio and lower temperature are favorable. However, the incremental improvement in the effect quickly slows down after exceeding the steam to $\mathrm{CO}$ ratio over 5:1. Higher steam:CO ratio might penalize the overall process by reducing available steam for power generation or other heating purposes. So, an optimum of 5:1 steam:CO ratio can be adequate to get a satisfactory conversion. Similarly, a lower optimum of $315-350{ }^{\circ} \mathrm{C}$ could be chosen as the operating temperature without compromising the yield.

\subsection{MEA Solvent to $\mathrm{CO}_{2}$ Mass Ratio}

The Mass ratio of MEA solvent to $\mathrm{CO}_{2}$ at the inlet of the absorber was varied between 3.5 to 22 . For each ratio, the amount of $\mathrm{CO}_{2}$ captured had been observed, along with the reboiler duty for the regeneration column. The amount of $\mathrm{CO}_{2}$ being absorbed was between $30 \%$ to $85 \%$ for low to high ratios. The result is visualized in Fig $4 \mathrm{a}$ and $\mathrm{b}$. With increasing MEA solution, absorption of $\mathrm{CO}_{2}$ increases but results in a higher flow rate and reboiler duty in the regeneration column causing a significant energy penalty.

From the observed trend of Reboiler duty and MEA solution to $\mathrm{CO}_{2}$ ratio with the percentage of capture, it is apparent that higher $\mathrm{CO}_{2}$ capture will require more energy and solvent. From the graph, up to $70 \%$ capture, reboiler duty increased at a comparatively lower rate. However, above this point, 


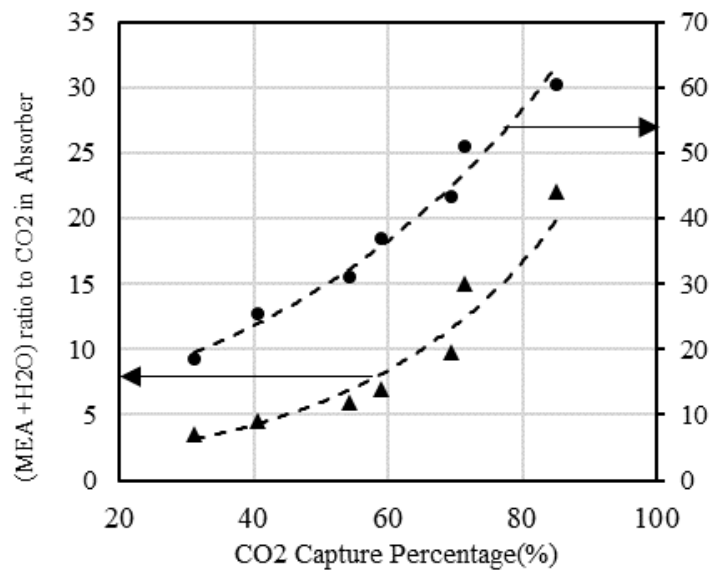

Fig 4 Effect of desired carbon capture percentage on MEA solution: $\mathrm{CO}_{2}$ mass ratio and Reboiler Duty of regeneration column

for a small percentage increment in the capture, reboiler duty increased markedly. Thus, to avoid the energy penalty, $70 \%$ capture can be selected as an optimum value to achieve satisfactory results.

\section{Conclusion}

A parametric study was performed to observe the effects on output variables by changing different input parameters. The CGE of the gasifier changed non-linearly from $65 \%$ to $70 \%$ when the Coal: MSW ratio was varied from 0.5 to 2 , concluding that it is sufficient to operate at a 1:1 ratio. In contrast, CGE varied from $72 \%$ to $56 \%$ for an inlet moisture content of $10 \%$ to $30 \%$. Variation of Steam: CO ratio showed that higher Steam: CO ratio has increased conversion. It was found that the Steam: CO ratio can be chosen at around 5:1 to have the maximum impact. Although low temperature favors conversion, it decreases the reaction rate. At around $300^{\circ} \mathrm{C}$, the conversion of $\mathrm{CO}$ is $\sim 95 \%$ which is satisfactory. A remarkable feature of the modeled process is the reduction of $\mathrm{CO}_{2}$ emission besides producing power. Percentage of $\mathrm{CO}_{2}$ capture should not be chosen beyond $70 \%$, as it requires a high ratio of MEA solution: $\mathrm{CO}_{2}$ and higher reboiler duty which causes energy penalty. Overall, the net emission from $\mathrm{CO}_{2}$ from fossil sources was $360 \mathrm{~kg} / \mathrm{MWh}$. Though these kinds of processes' energy efficiencies are at around 30\%, it could be an effective solution for municipal waste and reduce $\mathrm{CO}_{2}$ emission as a low carbon technology.

\section{References}

[1] R. Clark, N. Zucker, and J. Urpelainen, "The future of coal-fired power generation in Southeast Asia," Renew. Sustain. Energy Rev., vol. 121, no. December 2019, pp. 109650, 2020.

[2] G. A. S. Edwards, "Coal and climate change," Wiley Interdiscip. Rev. Clim. Chang., vol. 10, no. 5, pp. 1-16, 2019.

[3] A. Ryzhkov, T. Bogatova, and S. Gordeev, "Technological solutions for an advanced IGCC plant," Fuel, vol. 214, no. 14, pp. 63-72, 2018.

[4] A. A. Olajire, "A review of mineral carbonation technology in sequestration of CO2," J. Pet. Sci. Eng., vol. 109, pp. 364-392, 2013.

[5] M. G. Plaza and C. Pevida, Current status of CO2 capture from coal facilities. Elsevier, 2018.

[6] H. A. Long and T. Wang, "Parametric technoeconomic studies of coal/biomass co-gasification for IGCC plants with carbon capture using various coal ranks, fuel-feeding schemes, and syngas cooling methods," Int. J. Energy Res., vol. 40, no. 4, pp. 473496, Mar. 2016.

[7] C. Mukherjee, J. Denney, E. G. Mbonimpa, J. Slagley, and R. Bhowmik, "A review on municipal solid wasteto-energy trends in the USA," Renew. Sustain. Energy Rev., vol. 119, no. March 2019, pp. 109512, 2020.

[8] K. MA and W. John Taylor, "A comparative study of solid waste management in the United States, Europe and Asia," Ann. Civ. Environ. Eng., vol. 4, no. 1, pp. 003-011, 2020.

[9] S. K. Mani, WtE Best Practices and Perspectives in Asia, vol. 2013. Elsevier Inc., 2019.

[10] M. Hossein Sahraei, D. McCalden, R. Hughes, and L. A. Ricardez-Sandoval, "A survey on current advanced IGCC power plant technologies, sensors and control systems," Fuel, vol. 137, pp. 245-259, 2014.

[11] S. S. Dima, A. Arnob, U. Salma, K. B. Kabir, and K. Kirtania, "Fate of nutrients during hydrothermal carbonization of biogenic municipal waste," Biomass Convers. Biorefinery, 2020.

[12] M. S. Islam, A. Sultana, M. Rasheduzzaman, G. K. Kundu, A. K. I. Kamal, and M. K. Uddin, "Assessment of the Present State and Economical Prospects of Solid Waste at Amin Bazar Waste Dumping Site, Dhaka, Bangladesh," J. Sci. Res., vol. 7, no. 3, pp. 129-137, 2015.

[13] T. Ahmed, "Emission Inventory from the Use of Coals and Policy Recommendations for Coal Utilization," MSc Thesis submitted to Bangladesh University of Engineering and Technology, 2018.

CB Bangladesh Uni. of Engg. \& Tech. 